\title{
EFISIENSI TENAGA KERJA PRODUKSI KAYU LAPIS MENGGUNAKAN METODE LINE BALANCING DI PT. HARJOHN TIMBER LTD
}

\author{
(The efficiency of labor plywood product with line balancing method in PT. Harjohn Timber Ltd)
}

\author{
Resta Rene Mondina, Emi Roslinda, Gusti Hardiansyah \\ Fakultas Kehutanan Universitas Tanjungpura, Jl. Daya Nasional Pontianak, 78124 \\ Email: reneresta@gmail.com
}

\begin{abstract}
An efficient production process can be seen from the production process planning method considering the components of production such as labor.This research aims to analyze the degree of efficiency the number of plywood production labor with method of linebalancingin PT. Harjohn Timber Ltd and analyse the level of efficiency of the production output of plywood with the method linebalancing in PT. Harjohn Timber Ltd. Research conducted from MarchApril 2019. This research uses the method of observation by measuring the work time the production process which is done by as much as 5 times and supported with interview techniques to some of the workforce by as much as 25 people. The analysis of the data used, namely line balancing methods such as work stations, balance delay, line efficiency, smoothness index and output production. The results showed that the efficiency of the production including labor efficient seen from the division of types of labour, balance delay, line efficiency, smoothness index and output production. Results of line efficiency of $84.62 \%$ which means the trajectory of plywood production have been efficient. The value of the balance delay amounted to $15.37 \%$ mean waiting time on the production have been minimal, while the value of smoothness index too large IE 181.80 production pathway that indicates that in this regard yet balance.
\end{abstract}

Keywords : efficiency, labor, line balancing

\section{PENDAHULUAN}

Proses produksi yang berjalan dengan baik dan lancar merupakan suatu hal yang sangat diharapkan oleh perusahaan. Menjaga proses produksi agar dapat berjalan dengan baik, diperlukan metode perencanaan proses produksi yang baik dalam perusahaan (Raharja, 2014). Metode perencanaan proses produksi memiliki komponen produksi seperti tenaga kerja yang perlu diperhatikan. Tenaga kerja merupakan salah satu faktor produksi yang penting. Tingkat efisiensi tenaga kerja salah satunya dapat diketahui dengan melihat keseimbangan lintasan produksi suatu kegiatan proses produksi.

PT. Harjohn Timber Ltd merupakan perusahaan yang memproduksi plywood (kayu lapis) yang didukung oleh sejumlah mesin dan peralatan yang saling berinteraksi. Penggunaan tenaga kerja harus mampu mengimbangi efisiensi perusahaan karena perusahaan juga menggunakan mesin dalam proses produksi. Jika permintaan mengalami peningkatan maka akan memberikan dampak terhadap peningkatan volume pekerjaan, seperti tenaga kerja dan kemampuan mesin produksi yang tidak 
seimbang dalam mengolah bahan baku. Hal tersebut menyebabkan terjadinya penumpukkan material pada lintasan stasiun kerja. Penumpukkan material pada aliran produksi kayu lapis terjadi pada hasil pengupasan log oleh mesin rotary, dimana finir yang dihasilkan lebih banyak daripada kemampuan mesin dryer dalam mengeringkan finir tersebut. Selain dari mesin rotary, jika beberapa mesin memiliki kemampuan pengolahan yang berbeda, maka finir yang telah diolah dengan mesin sebelumnya harus menunggu giliran untuk dikerjakan. Adanya waktu tunggu pada beberapa stasiun kerja mengakibatkan terjadinya peningkatan balance delay. Berdasarkan pengamatan pada stasiun kerja, perusahaan menekankan pada spesifikasi kemampuan dan keahlian masing-masing operator sesuai dengan jenis pekerjaannya, sehingga terjadi ketidakseimbangan tenaga kerja jika stasiun kerja lain mengalami kendala.

Keadaan mesin yang membantu proses produksi kayu lapis termasuk dalam mesin dengan tahun instalasi 1980an, sehingga saat proses produksi berlangsung sering terjadi kerusakan pada beberapa mesin secara tiba - tiba. Sebagai contoh mesin minami (core builder) yang cukup sering mengalami kerusakan dan perlu diperbaiki saat proses produksi berlangsung. Hal ini tentu akan mempengaruhi waktu kerja dari elemen kerja tersebut dan akan menghambat aliran produksi. Mengingat bahwa perusahaan akan memproduksi kayu lapis secara massal, maka metode dan elemen-elemen kerja yang sama dilakukan berulang-ulang secara langsung. Salah satu cara untuk mengatasi ketidakseimbangan line adalah dengan melakukan keseimbangan pada lini perakitan (line balancing). Efficiency line yang rendah dan balance delay yang tinggi memberi dampak negatif secara langsung terhadap proses produksi suatu perusahaan.

Metode line balancing merupakan suatu penyeimbangan penugasan yang dikelompokkan dalam stasiun-stasiun kerja yang saling berkaitan dalam satu lintasan. Ristumadin (2015) line balancing merupakan penyeimbangan penugasan elemen-elemen tugas dari suatu assembly line ke work stations untuk meminimumkan banyaknya work station dan meminimumkan total harga idle time pada semua stasiun untuk tingkat output tertentu. Penyeimbangan tugas ini membutuhkan waktu per unit produk yang dispesifikasikan untuk setiap tugas dan hubungan sekuensial yang harus dipertimbangkan. Keseimbangan lini produksi bermula dari lini produksi massal, dimana dalam proses produksinya harus dibagikan pada seluruh operator sehingga beban kerja operator merata. Jadi, dalam keseimbangan lini produksi kita dapat merancang bagaimana seharusnya suatu lintasan produksi sehingga dapat tercapai keseimbangan beban yang dialokasikan pada setiap stasiun kerja dalam menghasilkan produk.

Penelitian ini bertujuan untuk menganalisa tingkat efisiensi tenaga kerja produksi kayu lapis dengan metode Line Balancing di PT. Harjohn Timber Ltd dan menganalisa tingkat efisiensi output produksi kayu lapis dengan metode Line 
Balancing di PT. Harjohn Timber Ltd. Hasil penelitian ini diharapkan dapat menjadi referensi dan salah satu bahan pertimbangan untuk menentukan kebijakan perusahaan, khususnya yang berkaitan dengan efisiensi tenaga kerja.

\section{METODE PENELITIAN}

Penelitian ini dilaksanakan di Pabrik Kayu Lapis PT. Harjohn Timber Ltd Desa Kuala Dua, Kumpai Kecamatan Sungai Raya, Kabupaten Kubu Raya, Kalimantan Barat dalam kurun waktu \pm 4 minggu dilapangan (04 Maret - 04 April 2019). Peralatan yang digunakan antara lain; logbook, laptop, kamera, stopwatch, perekam, dan kuesioner. Obyek dari penelitian adalah proses produksi kayu lapis seperti log cuting, log charger, rotary, dryer, F/B composer, core builder, repair core, repair $F / B, F / B$ core setting, glue spreader, cold press, hotpress, size sander, PPC, inspection, quality control, laboratorium, dan pihak-pihak perusahaan PT. Harjohn Timber Ltd. Penelitian menggunakan metode observasi dengan mengukur waktu kerja proses produksi dan didukung dengan teknik wawancara kepada beberapa tenaga kerja. Pengukuran waktu kerja dilakukan sebanyak 5 kali ulangan sebagai waktu baku yang digunakan untuk menentukan efisiensi sistem. Pengambilan sampel dilakukan kepada 25 orang tenaga kerja yang mewakili setiap proses produksi kayu lapis. Analisis data yang digunakan yakni metode line balancing seperti, balance delay, efisiensi lintasan, smothness index, dan output produksi.

Teknik pengumpulan data dilakukan dengan dua cara yaitu pengumpulan data secara langsung dari perusahaan berupa pengukuran waktu produksi setiap elemen kerja dan wawancara terhadap tenaga kerja produksi kayu lapis. Pengumpulan data dilapangan dilakukan sebanyak 5 kali dan dilakukan berurutan sesuai urutan proses produksi. Pengukuran waktu kerja dilakukan untuk memperoleh waktu baku yang akan diolah menjadi waktu stasiun kerja terbesar, waktu sebenarnya pada stasiun kerja, waktu operasi pada lintasan, waktu siklus, waktu maksimum stasiun kerja ke-i, dan waktu stasiun di stasiun kerja ke-i. Waktu baku diperoleh dari pengujian data yang mencakup uji keseragaman data dan uji kecukupan data yang memperhatikan faktor penyesuaian dan faktor kelonggaran yang diberikan untuk menjaga ketidakwajaran dalam bekerja. Waktu baku selanjutnya dianalisa dengan mengukur tingkat efisiensi proses produksi pada keadaan awal lintasan produksi menggunakan analisis keseimbangan lintasan dengan metode line balancing. Langkah dengan metode line balancing yaitu menyusun precedence diagram, menentukan posisi elemen kerja pada stasiun kerja sesuai susunan precedence diagram, menentukan balance delay, menentukan efisiensi lintasan, menentukan smoothness index dan menentukan output produksi.

Pengolahan data pertama dilakukan dengan pengujian data yang mencakup uji keseragaman data dan uji kecukupan data, perhitungan waktu normal dan waktu baku dengan menambahkan faktor penyesuaian dan faktor kelonggaran yang diberikan untuk menjaga ketidakwajaran dalam bekerja. Berikut teknik analisis data waktu 
baku untuk menentukan efisiensi sistem, yaitu :

1. Uji Kecukupan dan Keseragaman data Jika nilai $\mathrm{N}^{\prime} \leq \mathrm{N}$, maka data dianggap cukup. Penentuan nilai uji kecukupan data (N') dilakukan dengan rumus sebagai berikut (Purnomo, 2004):

$N^{\prime}=\left[\frac{\frac{k}{s} \sqrt{N\left(\sum x i^{2}\right)-\left(\sum x i\right)^{2}}}{\sum x i}\right]^{2}$

Keterangan:

$\mathrm{N} \quad=$ Jumlah data

$\mathrm{N}^{\prime} \quad=$ Jumlah data teoritis

$\mathrm{K}=$ Tingkat keyakinan

Jika tingkat keyakinan 99\%, maka $=2,58 \approx 3$

Jika tingkat keyakinan $95 \%$, maka $=1,96 \approx 2$

Jika tingkat keyakinan $68 \%$, maka $=1$

$\mathrm{S} \quad=$ Tingkat ketelitian

Jika tingkat ketelitian $99 \%$, maka $\mathrm{S}=1 \%$

Jika tingkat ketelitian 95\%, maka S $=5 \%$

Penentuan nilai uji keseragaman data dilakukan dengan rumus sebagai berikut (Syukron dan Kholil, 2017):

$$
\begin{gathered}
\sigma=\frac{\sqrt{\sum(x i-\bar{x})}}{n-1} \\
B K A=\bar{x}+k . \sigma \\
B K \mathrm{~B}=\bar{x}-k . \sigma
\end{gathered}
$$

Keterangan :

$\sigma \quad=$ standar deviasi

$\sum x i=$ jumlah data hasil pengamatan

$\bar{x} \quad=$ rata-rata data hasil pengamatan

$\mathrm{n} \quad=$ banyaknya jumlah data pengamatan

$k \quad=$ tingkat keyakinan

BKA = batas kontrol atas

$\mathrm{BKB}=$ batas kontrol bawah

Data yang diuji akan didapat batas kontrol, sehingga data dapat dikatakan seragam apabila berada diantara batas kontrol tersebut.

2. Perhitungan Waktu Normal dan Waktu

Baku

Perhitungan waktu normal dilakukan dengan rumus sebagai berikut (Rafian dan Muhsin, 2017):

$\mathrm{Wn}=\bar{x} \times(1+$ faktor penyesuaian $)$

Keterangan :

$\mathrm{Wn}=$ waktu normal (menit)

$\bar{x}=$ rerata waktu siklus pengamatan

Faktor penyesuaian $=$ angka performance rating dengan metode westing house

Perhitungan waktu baku atau waktu standar dilakukan dengan rumus sebagai berikut (Montororing, 2018)

$\mathrm{Ws}=\mathrm{Wn} \times(1+$ faktor kelonggaran $)$

Keterangan :

Ws = waktu standar atau waktu baku (menit) $\mathrm{Wn}=$ waktu normal (menit)

Faktor kelonggaran $=$ persentase kelonggaran

Pengukuran data menurut Azwir dan Pratomo (2017) menjelaskan terdapat beberapa parameter yang digunakan untuk mengukur performansi assembly line antara lain stasiun kerja (operator), balance delay, efficiency line dan smoothness index. Pernyataan tersebut sejalan dengan Ekoanindiyo dan Helmy (2017) yang menyatakan faktor pembanding analisis efisiensi sistem yaitu balance delay, efisiensi sistem, output yang dihasilkan, dan jumlah stasiun kerja. Berikut ini teknik analisis data efisiensi sistem dengan metode line balancing, yaitu :

a. Keseimbangan Waktu Senggang (Balance Delay)

Balance delay dapat diukur dengan rumus berikut (Purnomo, 2004):

$\mathrm{BD}=\frac{(N X C T)-\sum_{i=1}^{n} t i}{(N X C T)} \times 100 \%$

Dimana :

$\mathrm{N}=$ Jumlah stasiun kerja

$\mathrm{CT}=$ Waktu siklus

$\Sigma \mathrm{ti}=$ Jumlah dari seluruh waktu operasi

$\mathrm{BD}=$ Balance delay $(\%)$ 


\section{b. Efisiensi lintasan}

Efisiensi lintasan atau line efficiency dirumuskan sebagai berikut (Purnomo, 2004):

Line efficiency $=\frac{\sum S T i}{(N \times C T)}$ X $100 \%$

Dimana :

STi = Waktu stasiun kerja dari ke-i.

$\mathrm{N}=$ Jumlah stasiun kerja.

$\mathrm{CT}=$ Waktu siklus.

\section{c. Smoothes index}

Smoothness index atau indeks penghalusan dirumuskan sebagai berikut (Elsayed dan Boucher, 1994 dalam Azwir dan Pratomo, 2017) :

$\mathrm{SI}=\sqrt{ } \sum_{i=1}^{K}(S T \max -S T i)^{2}$

Dimana:

STmax = Waktu maks stasiun kerja ke-i

STi = Waktu stasiun di stasiun kerja ke-i

$\mathrm{K}=$ Jumlah stasiun kerja

\section{d. Output Produksi}

Output produksi rumus yang digunakan adalah sebagai berikut (Baroto, 2002 dalam Ekoanindiyo dan Helmy, 2017) :

$\mathrm{Q}=\frac{P}{C}$

Dimana:

$\begin{array}{ll}\mathrm{P} & =\text { Periode produksi } \\ \mathrm{C} & =\text { Waktu siklus } \\ \mathrm{Q} & \text { = Output produksi }\end{array}$

Pengumpulan data di lapangan juga dilakukan wawancara, yaitu dengan menggunakan kuesioner yang telah dipersiapkan sebelumnya. Isi daftar pertanyaan untuk responden terpilih meliputi kecukupan tenaga kerja, pembagian jenis tenaga kerja, waktu kerja, dan lamanya waktu tunggu. Berdasarkan hal tersebut diperoleh hasil wawancara yang dapat menyatakan tingkat efisien tenaga kerja di perusahaan.

HASIL DAN PEMBAHASAN

\section{Pengukuran Waktu Kerja}

Pengukuran waktu kerja dilakukan secara langsung di pabrik kayu lapis PT. Harjohn Timber Ltd dengan metode Jam Henti (Stopwatch). Pengukuran waktu kerja dengan metode jam henti dilakukan dengan cara kontinyu, yakni pengukuran dilakukan dengan memulai gerakan jarum jam henti pada permulaan pengerjaan elemen kerja pertama dan jarum jam henti tetap bergerak selama pengamatan berjalan (Wignjosoebroto, 2008). Metode pengukuran waktu kerja dengan jam henti dilakukan dengan cara mengamati dan menganalisa kegiatan produksi dengan mencatat waktu yang diperlukan suatu pekerjaan untuk menyelesaikan suatu operasi (Wignjosoebroto, 2008). Pernyataan tersebut sejalan dengan Purnomo (2004) yang menyatakan bahwa hasil pengukuran waktu dicatat pada lembar pengamatan. Hasil pengukuran selanjutnya dapat digunakan untuk menentukan waktu baku yang diperoleh untuk menyelesaikan suatu siklus pekerjaan yang dilaksanakan oleh pekerja yang sama (Supono dan Widodo, 2015). Data pengukuran waktu kerja produksi plywood terdapat pada Tabel 1 .

Berdasarkan data pengukuran waktu kerja (Tabel 1) terdapat 19 elemen kerja produksi kayu lapis yang diukur sebanyak 5 kali ulangan menggunakan stopwatch. Hasil pengukuran merupakan waktu proses produksi kayu lapis pada bahan plywood ukuran 86 mm x 945 mm x 1840 $\mathrm{mm}$ dan termasuk bahan floor base. Waktu kerja yang diukur pada proses produksi shift pagi yaitu pukul 07.00 18.00 WIB dan pada bulan Maret 2019. 
Rencana produksi plywood bahan $86 \mathrm{~mm}$ x $945 \mathrm{~mm}$ x $1840 \mathrm{~mm}$ pada bulan Maret adalah $6000 \mathrm{~m}^{3}$ yang dikerjakan dalam waktu 21 hari. Tahapan proses pengukuran dimulai dari log cutting sampai packing. Waktu elemen kerja terbesar yakni 55.32 menit terdapat pada elemen kerja cold press, karena waktu yang digunakan untuk mengempa kayu lapis yang telah dirakit. Sedangkan waktu elemen kerja terkecil yakni 1.16 menit tedapat pada elemen kerja log charger, karena waktu yang digunakan untuk membidik titik pusat $l o g$.

Tabel 1. Data pengukuran waktu kerja (Measurement of work time)

\begin{tabular}{|c|c|c|c|c|c|c|c|c|}
\hline \multirow[t]{2}{*}{ No. } & \multirow[t]{2}{*}{ EK } & \multicolumn{5}{|c|}{ Waktu Kerja (menit) } & \multirow{2}{*}{$\begin{array}{c}\text { Total } \\
\text { waktu } \\
\text { kerja }\end{array}$} & \multirow{2}{*}{$\begin{array}{l}\text { Rerata } \\
\text { (menit) }\end{array}$} \\
\hline & & 1 & 2 & 3 & 4 & 5 & & \\
\hline 1. & LC & 12.23 & 12.08 & 12.04 & 12.25 & 11.18 & 59.78 & 11.96 \\
\hline 2. & LCh & 01.14 & 01.23 & 01.20 & 01.11 & 01.13 & 5.81 & 1.16 \\
\hline 3. & $\mathrm{R}$ & 04.41 & 05.05 & 05.03 & 05.05 & 05.03 & 24.57 & 4.91 \\
\hline 4. & $\mathrm{RC}$ & 03.52 & 03.53 & 03.55 & 03.52 & 03.53 & 17.65 & 3.53 \\
\hline 5. & $\mathrm{AC}$ & 21.27 & 21.20 & 21.16 & 22.27 & 21.15 & 107.05 & 21.41 \\
\hline 6. & $\mathrm{CD}$ & 22.51 & 22.47 & 22.45 & 22.50 & 22.53 & 112.46 & 22.49 \\
\hline 7. & $\mathrm{RD}$ & 50.35 & 49.18 & 49.22 & 50.08 & 50.07 & 248.90 & 49.78 \\
\hline 8. & F/B Com & 18.39 & 17.13 & 18.57 & 18.51 & 18.35 & 90.95 & 18.19 \\
\hline 9. & CB & 42.10 & 44.01 & 40.57 & 41.20 & 42.18 & 210.06 & 42.01 \\
\hline 10. & F/B C set & 20.12 & 23.06 & 22.11 & 20.56 & 21.48 & 107.33 & 21.46 \\
\hline 11. & GS & 20.03 & 21.00 & 22.24 & 22.30 & 20.02 & 105.59 & 21.12 \\
\hline 12. & $\mathrm{CP}$ & 58.04 & 54.08 & 53.22 & 54.25 & 57.03 & 276.62 & 55.32 \\
\hline 13. & HP & 13.34 & 13.13 & 13.39 & 13.11 & 13.17 & 66.04 & 13.23 \\
\hline 14. & Rep & 09.29 & 09.13 & 09.54 & 09.24 & 10.43 & 47.63 & 9.53 \\
\hline 15. & $\mathrm{DSz}$ & 06.12 & 06.22 & 06.47 & 06.30 & 06.34 & 31.45 & 6.89 \\
\hline 16. & S & 06.10 & 06.39 & 06.10 & 06.18 & 06.37 & 31.14 & 6.23 \\
\hline 17. & Put & 08.25 & 08.57 & 08.54 & 08.22 & 08.36 & 41.94 & 8.38 \\
\hline 18. & Grad & 45.17 & 45.20 & 45.37 & 46.02 & 45.41 & 227.17 & 45.53 \\
\hline 19. & Pack & 03.20 & 03.31 & 03.08 & 03.00 & 03.26 & 15.85 & 3.17 \\
\hline
\end{tabular}

Sumber : Analisis Data, 2019

Keterangan

EK : Elemen kerja

L : : Log cutting

LCh : Log charger

$\mathrm{R} \quad$ : Rotary

$\mathrm{RC} \quad$ : Rotary core

AC : Arisun cliper

CD : Continuous dryer

RD : Roll dryer

F/B Comp: Face back composer

CB : Core builder

$\begin{array}{ll}\text { F/B C S } & : \text { Face back core setting } \\ \text { GS } & : \text { Glue spider } \\ \text { CP } & : \text { Cold press } \\ \text { Rep } & : \text { Repair veneer } \\ \text { HP } & : \text { Hot press } \\ \text { DSz } & \text { : Double sizer } \\ \text { S } & \text { : Sander } \\ \text { Put } & : \text { Putty } \\ \text { Finish } & \text { :Finishing, Packing }\end{array}$

\section{Uji Kecukupan dan Keseragaman Data}

Pengujian kecukupan data dan keseragaman data dilakukan berdasarkan tingkat keyakinan 95\%

sebesar 5\% (Septian dan Astuti, 2017). Pengujian kecukupan data diketahui dengan memperhatikan nilai $N^{\prime} \leq N$, dimana $\mathrm{N}$ bernilai 5 dan $\mathrm{N}^{\prime}$ bernilai banyaknya pengukuran yang 
diperlukan. Pengujian keseragaman data dilakukan dengan menentukan batas kontrol atas dan batas kontrol bawah. Keseragaman data elemen kerja $\log$ cutting telah memenuhi syarat, yakni rata - rata waktu kerja (11.96) berada diantara batas kontrol atas (13.06) dan batas kontrol bawah (10.86). Hasil uji keseragaman data pada elemen kerja $\log$ cutting disajikan dalam grafik pada Gambar 1.

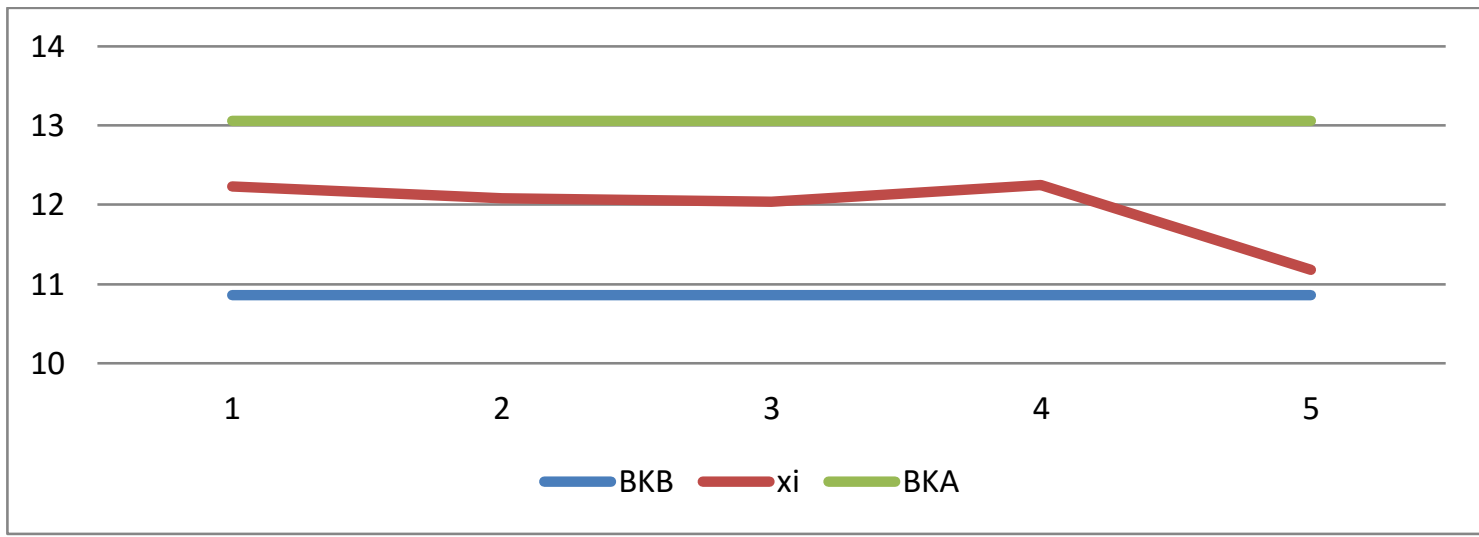

Gambar 1. Uji keseragaman data elemen kerja log cutting

Pengujian keseragaman data (Gambar 1) merupakan pengujian untuk elemen kerja log cutting, sedangkan hasil Tabel 2. Data hasil pengujian kecukupan dan keseragaman data (Result of sufficiency and uniformty data)

\begin{tabular}{|c|c|c|c|c|c|c|c|c|c|c|c|c|}
\hline No & EK & $\bar{x}$ & $\sum \mathrm{x}$ & $\sum \mathrm{x}^{2}$ & $\mathrm{~N}^{\prime}$ & $\begin{array}{l}\text { HasilU } \\
\text { jiKecu } \\
\text { kupan }\end{array}$ & Max & Min & $\sigma$ & BKA & BKB & $\begin{array}{c}\text { HasilUji } \\
\text { Keseraga } \\
\text { man }\end{array}$ \\
\hline 1. & $\mathrm{LC}$ & 11.96 & 59.78 & 3573.64 & 1.75 & $\mathrm{C}$ & 12.25 & 12.04 & 0.55 & 13.06 & 10.86 & $\mathrm{~S}$ \\
\hline 2. & $\mathrm{LCh}$ & 1.16 & 5.81 & 6.76 & 2.36 & $\mathrm{C}$ & 1.23 & 1.11 & 0.06 & 1.29 & 1.03 & S \\
\hline 3. & $\mathrm{R}$ & 4.91 & 23.57 & 603.68 & 4.21 & $\mathrm{C}$ & 5.05 & 4.41 & 0.32 & 5.55 & 4.27 & S \\
\hline 4. & $\mathrm{RC}$ & 3.53 & 17.65 & 311.52 & 4.62 & $\mathrm{C}$ & 3.55 & 3.52 & 0.01 & 3.56 & 3.49 & S \\
\hline 5. & $\mathrm{AC}$ & 21.41 & 107.05 & 11459.70 & 0.65 & $\mathrm{C}$ & 22.27 & 21.15 & 0.78 & 22.97 & 19.85 & S \\
\hline 6. & $\mathrm{CD}$ & 22.49 & 112.46 & 12647.25 & 0.01 & $\mathrm{C}$ & 22.53 & 22.45 & 0.03 & 22.55 & 22.43 & S \\
\hline 7. & $\mathrm{RD}$ & 49.78 & 248.90 & 61951.21 & 0.15 & $\mathrm{C}$ & 50.35 & 49.18 & 0.72 & 51.84 & 48.32 & S \\
\hline 8. & $\begin{array}{l}\text { F/B } \\
\text { Com }\end{array}$ & 18.19 & 90.95 & 8271.90 & 1.38 & $\mathrm{C}$ & 18.57 & 17.13 & 0.95 & 20.09 & 16.29 & S \\
\hline 9. & $\mathrm{CB}$ & 42.01 & 210.06 & 44125.20 & 1.22 & $\mathrm{C}$ & 44.01 & 40.57 & 2.05 & 46.11 & 37.91 & S \\
\hline 10. & $\begin{array}{l}\text { F/B C } \\
\text { set }\end{array}$ & 21.46 & 107.33 & 11519.72 & 3.88 & $\mathrm{C}$ & 23.06 & 20.12 & 1.78 & 25.02 & 17.90 & $S$ \\
\hline 11. & GS & 21.12 & 105.59 & 11149.24 & 3.63 & $\mathrm{C}$ & 22.30 & 20.02 & 1.38 & 23.88 & 18.36 & S \\
\hline 12. & $\mathrm{CP}$ & 55.32 & 276.62 & 76518.62 & 1.82 & $\mathrm{C}$ & 58.04 & 53.22 & 2.51 & 60.34 & 50.30 & $S$ \\
\hline 13. & HP & 13.23 & 66.04 & 4374.49 & 0.13 & $\mathrm{C}$ & 13.39 & 13.11 & 0.22 & 13.67 & 12.79 & $S$ \\
\hline 14. & Rep & 9.53 & 47.63 & 2268.61 & 3.92 & $\mathrm{C}$ & 10.43 & 9.13 & 0.65 & 10.83 & 8.23 & S \\
\hline 15. & $\mathrm{DSz}$ & 6.89 & 31.45 & 989.10 & 0.55 & $\mathrm{C}$ & 6.47 & 6.12 & 0.16 & 7.21 & 6.57 & $S$ \\
\hline 16. & $\mathrm{~S}$ & 6.23 & 31.14 & 969.69 & 0.67 & $\mathrm{C}$ & 6.39 & 6.10 & 0.22 & 6.67 & 5.79 & $S$ \\
\hline 17. & Put & 8.38 & 41.94 & 1758.96 & 0.47 & $\mathrm{C}$ & 8.57 & 8.22 & 0.24 & 8.84 & 7.92 & $S$ \\
\hline 18. & Grad & 45.53 & 227.17 & 51606.21 & 0.07 & $\mathrm{C}$ & 46.02 & 45.17 & 0.45 & 46.33 & 44.53 & S \\
\hline 19. & Pack & 3.17 & 15.85 & 251.22 & 2.10 & $\mathrm{C}$ & 3.31 & 3.00 & 0.19 & 3.55 & 2.79 & $S$ \\
\hline
\end{tabular}

Sumber : Analisis Data, 2019

Keterangan

EK : Elemen kerja

$\bar{x} \quad$ : Rata-rata

N' : Jumlah data teoritis

C : Cukup pengujian keseragaman data elemen kerja lain dapat dilihat pada Tabel 2 berikut. 
Perhitungan Waktu Normal dan Waktu Baku

Perhitungan waktu normal dan waktu standar setiap elemen kerja merupakan perhitungan yang didasarkan pada waktu rata-rata pengukuran dengan memperhitungkan faktor-faktor penyesuaian dan faktorfaktor kelonggaran. Perhitungan waktu normal dan waktu standar selengkapnya untuk elemen kerja dapat dilihat pada Tabel 3.

Tabel 3 menunjukkan bahwa waktu normal didapat dengan menentukan performance rating yang terdiri dari empat kelas. Jika nilai performance rating sebesar 0.00 maka operator pada elemen kerja memiliki nilai penyesuaian beberapa faktor yang average dan termasuk dalam kelas D dari keenam kelas yang dimiliki tiap faktor. Hasil faktor penyesuaian atau performance rating (Tabel 3) sejalan dengan penelitian Supono dan Widodo (2015) yang memiliki nilai penyesuaian faktor rata - rata average dan termasuk dalam kelas D

Tabel 3. Data hasil waktu normal dan waktu standar setiap elemen kerja (Result time normal and standar time elements of work)

\begin{tabular}{|c|c|c|c|c|c|c|c|c|c|c|}
\hline \multirow[t]{2}{*}{ No } & \multirow[t]{2}{*}{ EK } & \multirow[t]{2}{*}{$\bar{x}$} & \multicolumn{4}{|c|}{ Performance rating } & \multirow{2}{*}{$\begin{array}{c}\text { Total } \\
\text { performance } \\
\text { rating }\end{array}$} & \multirow[t]{2}{*}{ WN } & \multirow{2}{*}{$\begin{array}{l}\text { Allow- } \\
\text { ance }\end{array}$} & \multirow[t]{2}{*}{ WS } \\
\hline & & & Skill & Effort & Condition & Consistency & & & & \\
\hline 1. & LC & 11.96 & 0.00 & 0.00 & 0.00 & 0.00 & 0.00 & 11.96 & 0.29 & 15.43 \\
\hline 2. & LCh & 1.16 & 0.03 & 0.00 & 0.00 & 0.00 & 0.03 & 1.19 & 0.29 & 1.53 \\
\hline 3. & $\mathrm{R}$ & 4.91 & 0.03 & 0.02 & 0.00 & 0.00 & 0.05 & 5.15 & 0.29 & 6.64 \\
\hline 4. & $\mathrm{RC}$ & 3.53 & 0.03 & 0.02 & 0.00 & 0.00 & 0.05 & 3.70 & 0.29 & 4.77 \\
\hline 5. & $\mathrm{AC}$ & 21.41 & 0.00 & 0.00 & 0.00 & 0.00 & 0.00 & 21.41 & 0.29 & 27.61 \\
\hline 6. & CD & 22.49 & 0.00 & 0.00 & 0.00 & 0.00 & 0.00 & 22.49 & 0.29 & 29.01 \\
\hline 7. & RD & 49.78 & 0.00 & 0.00 & 0.00 & 0.00 & 0.00 & 49.78 & 0.29 & 64.21 \\
\hline 8. & $\begin{array}{l}\mathrm{F} / \mathrm{B} \\
\mathrm{Com}\end{array}$ & 18.19 & 0.03 & 0.02 & 0.00 & 0.00 & 0.05 & 19.09 & 0.29 & 24.62 \\
\hline 9. & $\mathrm{CB}$ & 42.01 & 0.03 & 0.03 & 0.00 & 0.00 & 0.05 & 44.11 & 0.29 & 56.90 \\
\hline 10. & $\begin{array}{l}\text { F/B C } \\
\text { set }\end{array}$ & 21.46 & 0.03 & 0.02 & 0.00 & 0.00 & 0.05 & 22.53 & 0.29 & 29.06 \\
\hline 11. & GS & 21.12 & 0.00 & 0.00 & 0.00 & 0.00 & 0.00 & 21.12 & 0.29 & 27.24 \\
\hline 12. & $\mathrm{CP}$ & 55.32 & 0.00 & 0.00 & 0.00 & 0.00 & 0.00 & 55.32 & 0.29 & 71.36 \\
\hline 13. & HP & 13.23 & 0.03 & 0.02 & 0.00 & 0.00 & 0.05 & 13.89 & 0.29 & 17.91 \\
\hline 14. & Rep & 9.53 & 0.03 & 0.02 & 0.00 & 0.00 & 0.05 & 10.01 & 0.29 & 12.91 \\
\hline 15. & $\mathrm{DSz}$ & 6.89 & 0.00 & 0.00 & 0.00 & 0.00 & 0.00 & 6.89 & 0.29 & 8.88 \\
\hline 16. & S & 6.23 & 0.00 & 0.00 & 0.00 & 0.00 & 0.00 & 6.23 & 0.29 & 8.04 \\
\hline 17. & Put & 8.38 & 0.03 & 0.02 & 0.00 & 0.00 & 0.05 & 8.79 & 0.29 & 11.33 \\
\hline 18. & Grad & 45.53 & 0.03 & 0.02 & 0.00 & 0.00 & 0.05 & 47.40 & 0.29 & 61.53 \\
\hline 19. & Pack & 3.17 & 0.00 & 0.00 & $\begin{array}{l}0.00 \\
\text { Total }\end{array}$ & 0.00 & 0.00 & 3.17 & 0.29 & $\begin{array}{r}4.08 \\
483.08 \\
\end{array}$ \\
\hline
\end{tabular}

Sumber : Analisis Data, 2019

Keterangan :EK : Elemen kerja

$\bar{x} \quad$ : Rata-rata

WN : Waktu normal

WS : Waktu standar

Analisis Kondisi Terpasang

Stasiun kerja pada kondisi terpasang terdapat 8 stasiun kerja 
dimana jumlah elemen kerja untuk melakukan proses produksi kayu lapis dari persiapan log hingga pengepakan sebanyak 19 elemen kerja. Berdasarkan hasil pengukuran, total waktu standar yang dibutuhkan untuk 19 elemen kerja adalah 483.08 menit. Berikut adalah alokasi elemen kerja untuk masing masing stasiun kerja pada sistem terpasang atau yang sedang dikerjakan yang ditunjukkan pada Tabel 4 .

Tabel 4 menunjukkan bahwa waktu stasiun kerja terbesar terdapat pada stasiun kerja ke empat yakni 110.58 menit yang terdiri dari elemen kerja core builder, face back core setting, dan glue spreader. Sedangkan waktu stasiun kerja terkecil terdapat pada stasiun kerja ke delapan yakni 4.08 menit yang terdiri dari elemen kerja packing.

Tingkat performansi pada sistem terpasang menunjukkan perlu dilakukan beberapa perhitungan kriteria performansi (Tabel 5), yaitu meliputi balance delay, line efficiency, smoothness index dan output produksi. Perhitungan dilakukan untuk menentukan rancangan keseimbangan lintasan agar dapat menghasilkan output yang maksimal.

Tabel 4. Alokasi elemen kerja pada sistem terpasang (Allocation of work elements on the system installed)

\begin{tabular}{cccc}
\hline Stasiun Kerja & EK & WS (menit) & STi (menit) \\
\hline \multirow{2}{*}{ I } & LC & 15.43 & 16.96 \\
& LCh & 1.53 & 39.02 \\
II & R & 6.64 & \\
& RC & 4.77 & 93.22 \\
III & AC & 27.61 & \\
& CD & 29.01 & 110.58 \\
IV & RD & 64.21 & 27.24 \\
& F/B Com & 24.62 & 102.18 \\
V & CB & 56.90 & \\
& F/B C set & 29.06 & \\
VI & GS & 27.24 & \\
& CP & 71.36 & 17.91 \\
& HP & 12.91 & 93.86 \\
VII & Rep & 8.88 & 4.08 \\
\hline
\end{tabular}

Sumber : Analisis Data, 2019

$\begin{array}{lll}\text { Keterangan } & \text { EK } & \text { : Elemen kerja } \\ & \text { WS } & \text { : Waktu standar } \\ & \text { STi } & : \text { Waktu stasiun kerja ke-i }\end{array}$


Tabel 5. Parameter performansi (Parameter performance)

\begin{tabular}{llr}
\hline No. & Parameter & Metode line balancing \\
\hline 1. & Balance delay $(\mathrm{BD})$ & $15.37 \%$ \\
2. & Efisiensi lintasan & $84.62 \%$ \\
3. & Smoothess index (menit) & 181.80 \\
4. & Output produksi (unit/bulan) & 260 \\
\hline
\end{tabular}

Sumber : Analisis Data, 2019

\section{Balance delay}

Nilai balance delay pada sistem produksi dengan menerapkan metode line balancing adalah $15.37 \%$, dimana nilai tersebut tergolong kecil. Pernyataan tersebut sejalan dengan penelitian Ekoanandiyo dan Helmy (2017) menyatakan bahwa balance delay sebesar $15.41 \%$ memiliki balance delay yang nilainya kecil. Penyebab nilai balance delay yang kecil dikarenakan oleh tenaga kerja menggunakan waktu kerja semaksimal mungkin sehingga jarang terjadi waktu tunggu.

Efisiensi Lintasan

Hasil perhitungan efisiensi lintasan menunjukkan bahwa nilai line efficiency yang tinggi. Pernyataan tersebut sejalan dengan penelitian Arifiana dan Suletra (2017) menyatakan bahwa efisiensi lintasan yang tinggi sebesar 74,38\%. Nilai line efficiency yang tinggi dikarenakan saat pengamatan pekerja memanfaatkan waktu semaksimal mungkin hingga tidak terjadi waktu kosong.

Smoothness index

Perhitungan smoothness index dilakukan dengan indeks penghalusan untuk memiliki kelancaran relatif dalam suatu lintasan produksi (Purnomo, 2004). Nilai smoothness index sebesar
181.80 merupakan nilai yang tinggi untuk mencapai keseimbangan lintasan karena jauh dari angka nol. Dimana, jika nilai smoothness index semakin mendekati angka nol maka lintasan produksi seimbang. Pernyataan tersebut sejalan dengan penelitian Supono dan Widodo (2015) menyatakan bahwa nilai smoothness index yang jauh dari angka nol memiliki perfomansi lintasan yang kurang baik. Hal tersebut terjadi karena kurang tepat pengaturan dan perencanaan elemen kerja pada stasiun kerja yang diterapkan saat pengamatan dilakukan.

Nilai smoothness index pada proses produksi kayu lapis tidak dapat dijadikan acuan untuk mengetahui tingkat efisiensi waktu kerja, karena untuk memperkecil nilai smoothness index diperlukan perubahan elemen kerja yang akan digabungkan dengan stasiun kerja lain. Mengingat proses produksi kayu lapis memiliki sususan proses yang sudah baku, maka elemen kerja yang sudah ada tidak bisa digabungkan ke stasiun kerja lain. Misalnya, untuk meminimalisir waktu tunggu pada stasiun kerja ke VII, maka elemen kerja tersebut digabungkan ke stasiun kerja ke VI yang pada aplikasinya stasiun kerja tersebut tidak 
bisa digabung karena memiliki fungsi yang berbeda.

\section{Output produksi}

Jumlah keluaran yang dihasilkan selama bulan Maret 2019 sebanyak 994 unit sedangkan setelah menghitung ouput produksi menghasilkan nilai 260 unit pada bulan Maret. Oleh karena itu, keluaran yang dihasilkan pada bulan Maret 2019 melebihi batas output produksi yang seharusnya dikerjakan setiap bulan.

Tenaga kerja produksi kayu lapis PT. Harjohn Timber Ltd termasuk tenaga kerja terlatih, dimana sebelum melakukan pekerjaan untuk pertama kali pekerja diberi pelatihan mengenai bahan - bahan produksi kayu lapis. Efisiensi tenaga kerja produksi termasuk efisien dilihat dari hasil penelitian data primer dan data sekunder yakni pembagian jenis tenaga kerja, waktu kerja, lintasan produksi, jumlah stasiun kerja, keseimbangan waktu senggang, efisiensi lintasan, dan keluaran produksi.

Sistem produksi kayu lapis di PT. Harjohn Timber sudah berjalan dengan baik. Hal tersebut diuji dengan metode line balancing menggunakan beberapa analisis yaitu balance delay, efisiensi lintasan, smoothness index dan output produksi. Nilai balance delay sebesar $15.37 \%$ berarti waktu tunggu pada lintasan produksi telah minim karena pekerja berusaha untuk terus bekerja dengan memaksimalkan waktu kerja yang tersedia. Hasil efisiensi lintasan sebesar $84.62 \%$ yang berarti lintasan produksi kayu lapis telah efisien.
Sedangkan nilai smoothness index terlampau besar yakni 181.80 yang menandakan bahwa lintasan produksi dari segi ini belum seimbang karena nilai smoothness index jauh dari angka nol.

Analisis data menggunakan salah satu metode line balancing yakni Rank Positional Weigth tidak bisa dilakukan karena metode tersebut tidak bisa diterapkan pada industri kayu lapis yang memiliki urutan produksi yang sudah baku. Mengingat bahwa konsep dari metode RPW yakni mengurutkan elemen kerja yang memiliki bobot posisi terbesar ke urutan awal. Sebagai contoh, elemen kerja cold press memiliki waktu standar sebesar 71.36 menit, dimana jika dihitung bobot posisi maka elemen kerja cold press akan berada didekat elemen kerja log charger. Hal tersebut tidak mungkin diaplikasikan karena urutan proses produksi kayu lapis sudah baku. Jika metode tersebut tetap digunakan, maka hasil yang didapat untuk beberapa analisis data seperti balance delay bernilai negatif, efisiensi lintasan bernilai lebih dari $100 \%$, dan smoothness index tidak bisa dilakukan karena elemen kerja yang memiliki waktu terbesar akan berada di stasiun kerja pertama dan hal tersebut tidak bisa diaplikasikan.

\section{KESIMPULAN}

Berdasarkan kegiatan yang
dilakukan dalam penelitian maka
diambil kesimpulan bahwa:
1. Efisiensi tenaga kerja produksi dapat
diketahui dengan memperhatikan


aspek pembagian jenis tenaga kerja, waktu kerja, lintasan produksi, keseimbangan waktu senggang, efisiensi lintasan, dan keluaran produksi. Hal tersebut diuji dengan metode line balancing menggunakan beberapa analisis yaitu, balance delay, efisiensi lintasan, smoothness index dan output produksi. Berdasarkan hasil penelitian, tenaga kerja sudah termasuk efisien yang dilihat dari nilai hasil balance delay sebesar $15.37 \%$ berarti waktu tunggu pada lintasan produksi telah minim karena pekerja berusaha untuk terus bekerja dengan memaksimalkan waktu kerja yang tersedia. Nilai efisiensi lintasan sebesar $84.62 \%$ yang berarti lintasan produksi kayu lapis telah efisien. Sedangkan nilai smoothness index terlampau besar yakni 181.80 yang menandakan bahwa lintasan produksi dari segi ini belum seimbang karena nilai smoothness index jauh dari angka nol.

2. Tingkat efisiensi output produksi kayu lapis dengan menggunakan metode line balancing di PT. Harjohn Timber sudah tercapai dengan menghasilkan output sebesar 260 unit per bulan.

3. Tingkat efisiensi tenaga kerja produksi kayu lapis dinyatakan sudah baik. Hal tersebut dilihat dari pernyataan 25 orang tenaga kerja saat wawancara yang menyatakan bahwa, pemanfaatan waktu kosong diisi tenaga kerja dengan memaksimalkan waktu kerja yang tersedia seperti mengerjakan pekerjaan lain.

4. Penumpukkan material terjadi karena keterbatasan mesin yang bekerja saat proses produksi, kapasitas mesin yang berbeda - beda di setiap stasiun kerja dan tidak mempengaruhi tingkat efisiensi dari proses produksi.

\section{SARAN}

Berdasarkan kegiatan yang dilakukan dalam penelitian maka diambil kesimpulan bahwa:

1. Sebaiknya tetap mempertahankan prinsip tenaga kerja yang memaksimalkan pemanfaatan waktu tunggu ketika bekerja dan menjadwalkan kegiatan yang bisa dilakukan pekerja ketika mengalami waktu tunggu.

2. Penelitian hanya mengambil dari segi aspek waktu produksi dan belum mengenai tata letak line assembling perusahaan. Oleh karena itu, perlu dilakukan penelitian lebih lanjut mengenai tata letak produksi kayu lapis agar hasil rekomendasi dapat diaplikasikan.

3. Penelitian selanjutnya dilakukan pada kayu selain meranti yang digunakan sebagai hasil untuk ordinary ply atau gross grain.

4. Pengujian waktu produksi menggunakan metode lain seperti time study agar dapat menjadi referensi dalam sistem produksi kayu lapis.

\section{DAFTAR PUSTAKA}

Arifiana GSN, Suletra IW. 2017. Analisis Line Balancing dengan RPW

Departemen 
Assembly Line Style F1625W404 di PT. Pan Brothers, Boyolali. ISSN: 2579-6429 : 442-450.

Azwir HH, Pratomo HW. 2017. Implementasi Line Balancing untuk Peningkatan

Efisiensi Di Line Welding Studi Kasus: PT X. Jurnal Rekayasa Sistem Industri 6 (1): 57-63.

Ekoanindiyo FA, Helmy L. 2017. Meningkatkan Efisiensi Lintasan Kerja Menggunakan Metode RPW Dan Killbridge-Western. Jurnal Dinamika Teknik 10

(1): 16-26.

Montororing YDR. 2018. Usulan Penentuan Waktu Baku Proses Racking Produk Amplimesh dengan Metode Jam Henti pada Departemen Powder Coating. Jurnal Teknik 7 (2): 53-63.

Purnomo H. 2004. Pengantar Teknik Industri. Yogyakarta: Graha Ilmu.

Rafian MA, Muhsin A. 2017. Analisis Beban Kerja Mekanik Pada Departemen Plant Dengan Metode Work Sampling (Studi Kasus Pada PT. XYZ). Jurnal OPSI 10 (1): $35-42$.

Raharja I. 2014. Analisa Penjadwalan Proyek Dengan Metode PERT Di
PT Hasana Damai Putra Yogyakarta Pada Proyek Perumahan Tirta Sani. Jurnal Bentang 2 (1):81-94.

Ristumadin I. 2015. Analisa Produktivitas Dan Efisiensi Kerja Dengan Line Balancing Pada Area Lead Connection Di PTA. Jurnal OASTI 9 (3): 300-310.

Septian RD, Astuti RD. 2017. Analisis Efisiensi Karyawan untuk Meningkatkan Produktivitas pada Divisi Pengemasan Line Box di PT. MAK. Seminar dan Konferensi Nasional IDEC : 162170.

Supono J, Widodo T. 2015. Penerapan Metode Line Balancing Untuk Peningkatan Produktivitas Pada Jalur Lintasan CPLG EXTENSION di PT. ABC. Jurnal Teknik 4 (1):10-23.

Susan. 2013. Minimalisasi Bottleneck Proses Produksi Dengan Metode Line Balancing Pada PT. XYZ. Jurnal S1 Teknik Industri UNTAN 1 (3): 24-29.

Wignjosoebroto S. 2008. Ergonomi, Studi Gerak Waktu Teknik Analisis Untuk Peningkatan Produktivitas Kerja. Surabaya : Guna Widya. 